\title{
Effect of western U.S. snow cover on climate
}

\author{
Susan Marshall, ${ }^{1}$ Robert J. Oglesby, ${ }^{2}$ Anne W. Nolin ${ }^{3}$ \\ ${ }^{1}$ Department of Geography and Earth Sciences, University of North Carolina at Charlotte, Charlotte, NC 28223, U.S.A. \\ ${ }^{2}$ Department of Earth and Atmospheric Sciences, Purdue University, West Lafayette, IN 47907, U.S.A. \\ ${ }^{3}$ Cooperative Institute for Research in Environmental Sciences, University of Colorado, Boulder, CO 80309, U.S.A.
}

\begin{abstract}
The purpose of this study is to identify, characterize and quantify local, regional and remote effects of snow cover on western U.S. climate and water resources. An ensemble of predictability and sensitivity studies was made with the U.S. National Center for Atmospheric Research (NCAR) Community Climate Model, version 3 (CCM3) to investigate the relative roles of snow-cover anomalies and initial atmospheric states in the subsequent accumulation and ablation seasons. The suite of model experiments focuses on the direct effect of snow on regional climate anomalies and ultimately will be used to examine the lagged effect of anomalous snow cover on the climate. The set of ensemble simulations presented here looks at the climate-system response to anomalously high and low snow cover at the start of the ablation season over the western U.S.A. These current results suggest that the initial state of snow cover is more important than the initial state of the atmosphere or of sea-surface temperatures because of direct thermal effects on the surface and subsequent indirect, dynamical effects on the atmospheric circulation.
\end{abstract}

\section{INTRODUCTION}

Snow cover is not only a passive responder but also a forcing mechanism in climate variability. Documented relationships between snow cover on the land surface and climate variables indicate that snow cover affects lower tropospheric temperatures (Wagner, 1973; Dewey, 1977; Walsh and others, 1982; Baker and others, 1992; Leathers and others, 1995) and atmospheric circulation (Dickson and Namias, 1976; Heim and Dewey, 1984; Clark and Serreze, in press) on regional and possibly even hemispherical scales. The temperature- depression effect of snow on air temperatures is attributed to the higher albedo of the land surface when snow cover is present. This albedotemperature feedback is largest in the spring, when snow cover remains extensive and insolation is high (Groisman and others, 1994). Snow cover also lowers tropospheric air temperatures by redirecting surface energy inputs towards warming and melting/sublimating the snowpack (Groisman and others, 1997). Snow cover over Eurasia has been shown to affect the strength and onset of the summer monsoon and may appear to influence the strength of the monsoonal circulation over the western U.S.A. (see, e.g., Foster and others, 1983; Barnett and others, 1989; Cayan, 1996; Gutzler and Preston, 1997).

To date, most regional studies have focused on the examination of local-to-regional-scale relationships between snow and water resources, taking the viewpoint of snow cover as a passive responder to climate variability. This study considers snow not as a passive responder but as an active driver of climate variability, specifically over the western U.S.A. The research presented here describes a set of ensemble simulations using the U.S. National Center for Atmospheric Research (NCAR) Community Climate Model version 3 (CCM3) forced with anomalously high/low snow cover over the western U.S.A. The goal of this study is to evaluate the relative strengths of the effects of initial atmospheric conditions and initial snow-cover conditions on late-season snowcover persistence.

\section{MODEL DESGRIPTION: NGAR GGM3}

The global climate model used for this study is the NCAR Climate System Model (CSM) (Boville and Gent, 1998). The CSM includes atmospheric, oceanic, land-surface, and sea-ice components. The atmospheric component has a horizontal resolution of T42, or an equivalent grid resolution of $2.8^{\circ}$ latitude by $2.8^{\circ}$ longitude, and the vertical resolution is resolved by 18 layers. The standard land-surface option for CSM (and hence CCM3) is the Land Surface Model (LSM; Bonan, 1998). Soil and vegetation type and characteristics are prescribed and vary monthly. Soil temperatures and soil moisture are calculated using a six-layer soil energy and moisture model. The LSM incorporates components of the improved snow hydrology of Marshall and Oglesby (1994), including a variable snow-cover albedo and a surface albedo based on fractional snow/vegetation cover. Snow depth is determined using a simple mass and energy balance and assuming a constant snow density. Hack and others (1998) and Kiehl and others (1998) summarize important characteristics of the model-generated climate.

The model simulation used in this study is a 45 year CCM3 run with monthly sea-surface temperature (SST) for each year specified according to observations supplied by the U.S. National Centers for Environmental Prediction for the years 1958-98 (henceforth called CGM3/SST). Results from the CGM3/SSTrun can be directly compared to atmospheric observations on a year-to-year basis, with the caveat that the SST forcing is the only one that relates model years to actual calendar years (Oglesby and others, in press).

\section{EXPERIMENT DESIGN}

We designed and executed a set of four predictability experiments (see Table 1), based on years that had relatively high or low January, February and March snow anomalies over the 

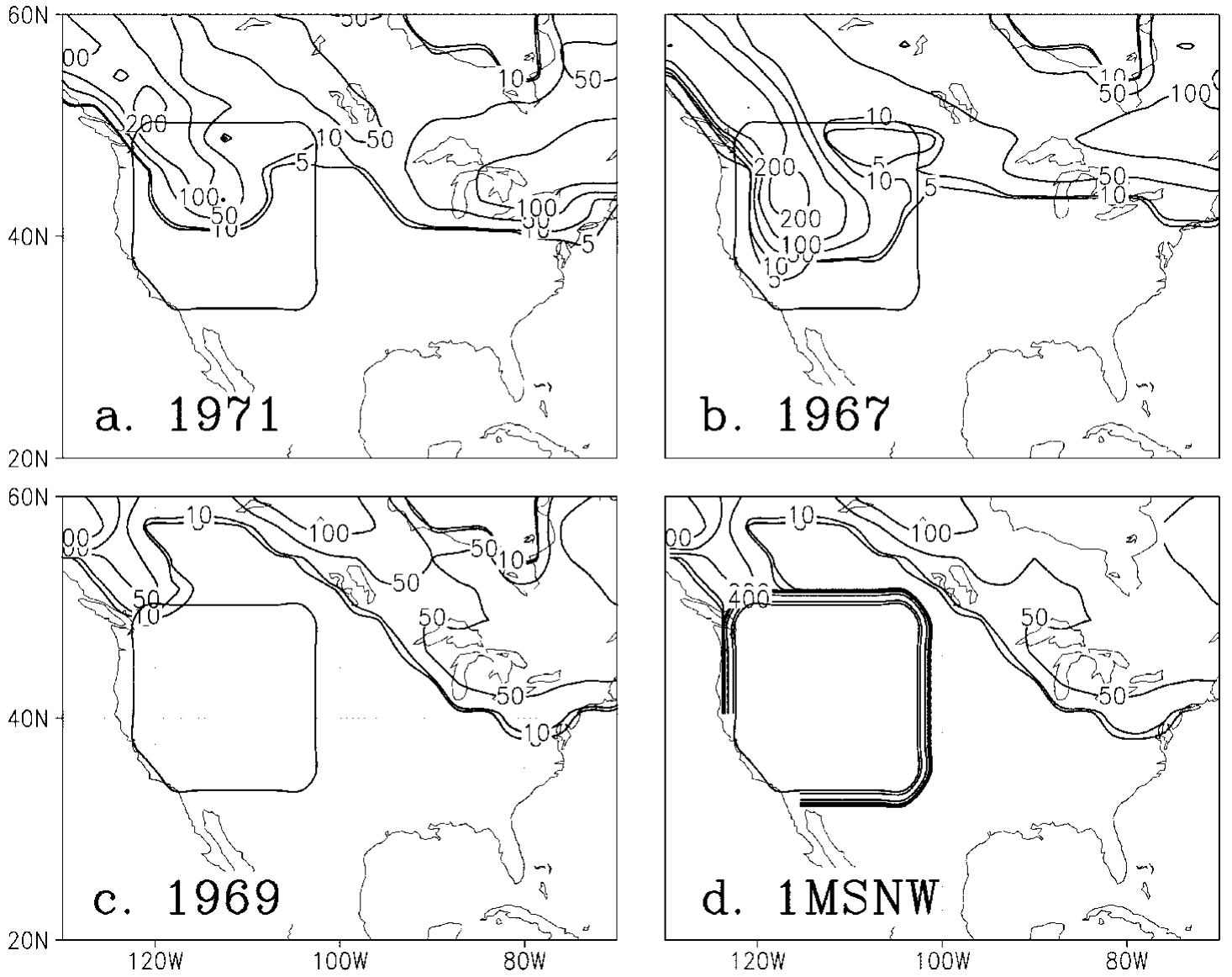

Fig. 1. Snow depths (mm w.e.) for 1 February showing (a) the "normal" initial conditions of snow cover for 1971, (b) the anomalously high snow cover of 1967, (c) the anomalously low snow cover of 1969, and $(d)$ the initial snow cover for the $1 \mathrm{~m}$ snow experiment. All panels indicate the extent of the western U.S. domain used in averaging.

western U.S.A. and that clearly demonstrated these anomalies on 1 February (Fig. 1). In each experiment we impose the global snow-cover state from these years as the initial anomaly to the perturbed run (this means that there are anomalies elsewhere on the globe). However, to perform proper predictability experiments we must use initial atmospheric and snow-cover states actually simulated by the model in the CGM3/SST run. Each experiment set contains an ensemble of five runs, all begun on 1 February radiation date, and as perturbation, using as initial conditions the atmospheric states obtained for 30 and 31 January and 1,2 and 3 February. The perturbation runs indicate the degree of inherent variability expected from the model.

SNWPRED1 and SNWPRED2 both have initial atmos-

Table 1. Basic predictability experiments

\begin{tabular}{llc}
\hline & \multicolumn{2}{c}{$\begin{array}{c}\text { Initial conditions } \\
\text { Atmosphere }\end{array}$} \\
& Surface \\
\hline SNWPRED1 & 1 February 1971 & High snow $^{*}$ \\
SNWPRED2 & 1 February 1971 & Low snow $^{\dagger}$ \\
SNWPRED3 & 1 February 1969 & Normal snow ${ }^{\ddagger}$ \\
SNWPRED4 & 1 February 1967 & Normal snow \\
1MSNW & 1 February 1967 & 1 m snow
\end{tabular}

*High snow corresponds to 1 February 1967 initial conditions.

${ }^{\dagger}$ Low snow corresponds to 1 February 1969 initial conditions.

${ }^{\ddagger}$ Normal snow corresponds to 1 February 1971 initial conditions. pheric states from a "normal" year (taken to be February 1971), but forced with either high (1 February 1967; SNWPRED1) or low (1 February 1969; SNWPRED2) initial snow-cover conditions. These experiments help assess the degree to which the subsequent extent of the snow cover depends solely on the initial state of the snow cover. SNWPRED3 and SNWPRED4 both have initial snow cover taken to be near climatological values for February, but initial atmospheric states for a high-snow period (1 February 1967; SNWPRED4) or a low-snow period (1 February 1969; SNWPRED3). The SSTs are selected from the same year as the initial atmospheric state. Thus, the only quantity we vary is the initial snow cover. These experiments assess the degree to which the high- or low-snow conditions depend solely on the initial state of the atmosphere.

To clarify the physical mechanisms by which snow cover can affect climate, we employ a simulation in which an extreme anomaly of $1 \mathrm{~m}$ snow cover water equivalent (1MSNW) is imposed over the western U.S. domain for the 1969 low-snow-cover-year atmosphere. The purpose of this treatment is to distinguish the effects of a snow-cover anomaly just over the western U.S. domain, as opposed to anomalies that may appear within the western domain and elsewhere.

\section{RESULTS AND DISGUSSION}

The following discussion groups the results into (a) high- 


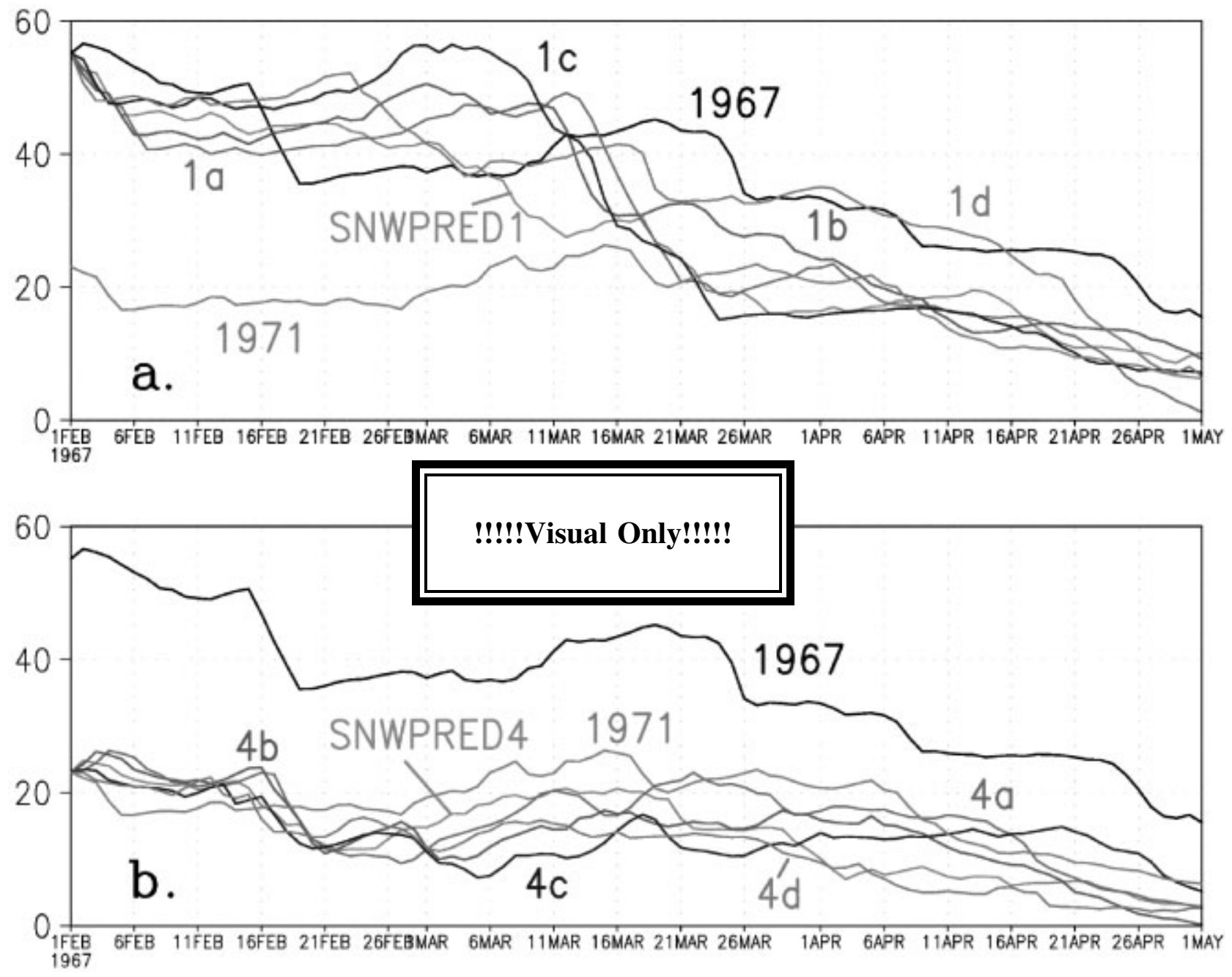

Fig. 2. Time series of SNWPRED1 (high initial snow cover, normal snow atmosphere) and SNWPRED4 (normal initial snow cover, high snow atmosphere) snow-cover depths ( $m$ m w.e.) compared to the control high-snow year (1967) and normal-snow year (1971). Experiments labeled a-d correspond to ensemble members using atmospheric initial conditions corresponding to 30 and 31 fanuary, 2 and 3 February respectively.

(1967) and (b) low- (1969) snow-cover events and (c) an imposed $1 \mathrm{~m}$ snow-cover anomaly, and compares:

(1) the ability of high- (low-) snow-cover events to perpetuate, given atmospheric states from normal snow-cover conditions during the accumulation season;

(2) the degree of forcing that the initial atmospheric state from high (low) snow cover exerts on the subsequent evolution of an initial snow cover set to the mean state;

(3) the physical processes by which anomalous snow cover can be an active participant in impacting the atmospheric state.

\section{High snow (1967 case)}

Figure 2 shows the results from the SNWPRED1 and SNWPRED4 simulations. As described above, the SNWPRED1 case is initialized with the high (1967) snow cover but uses the normal-snow-year (1971) atmospheric state. SNWPRED4 is initialized with a normal-snow-year (1971) snow cover but uses the high-snow-year (1967) atmospheric state. It is obvious that the SNWPREDl ensembles maintain the extensive initial snowpack for at least 6 weeks, despite an initial state of the atmosphere taken from the mean snow year of 1971 (Fig. 2a). The SNWPRED4 ensembles (Fig. 2b), on the other hand, main- tain the much lower initial snow cover of 1971, despite an initial atmospheric state taken from the high-snow year of 1967.

\section{Low snow (1969 case)}

Figure 3 shows the results from the SNWPRED2 and SNWPRED3 simulations. As described previously, the SNWPRED2 case is initialized with the low (1969) snow cover but uses the normal-snow-year (1971) atmospheric state. SNWPRED3 is initialized with a normal-snow-year (1971) snow cover but uses the low-snow-year (1969) atmospheric state. The SNWPRED2 ensembles clearly maintain the low initial snow cover of 1 February 1969 despite a mean initial state of the atmosphere. The SNWPRED3 ensembles maintain a much higher degree of snow cover than in the base 1969 case, despite an atmospheric initial state consistent with low-snow conditions. This figure clearly indicates the robustness of these results. SNWPRED2 and especially SNWPRED3 track the subsequent "normal" snow cover (1971) closely over the 90 day length of the runs.

These analyses suggest that the initial snow cover is much more important than the initial state of the atmosphere (or of the SSTs) in predicting the extent of snow cover for the next several months. This indicates some skill in predicting high (low) snow cover when such anomalies are found over the 

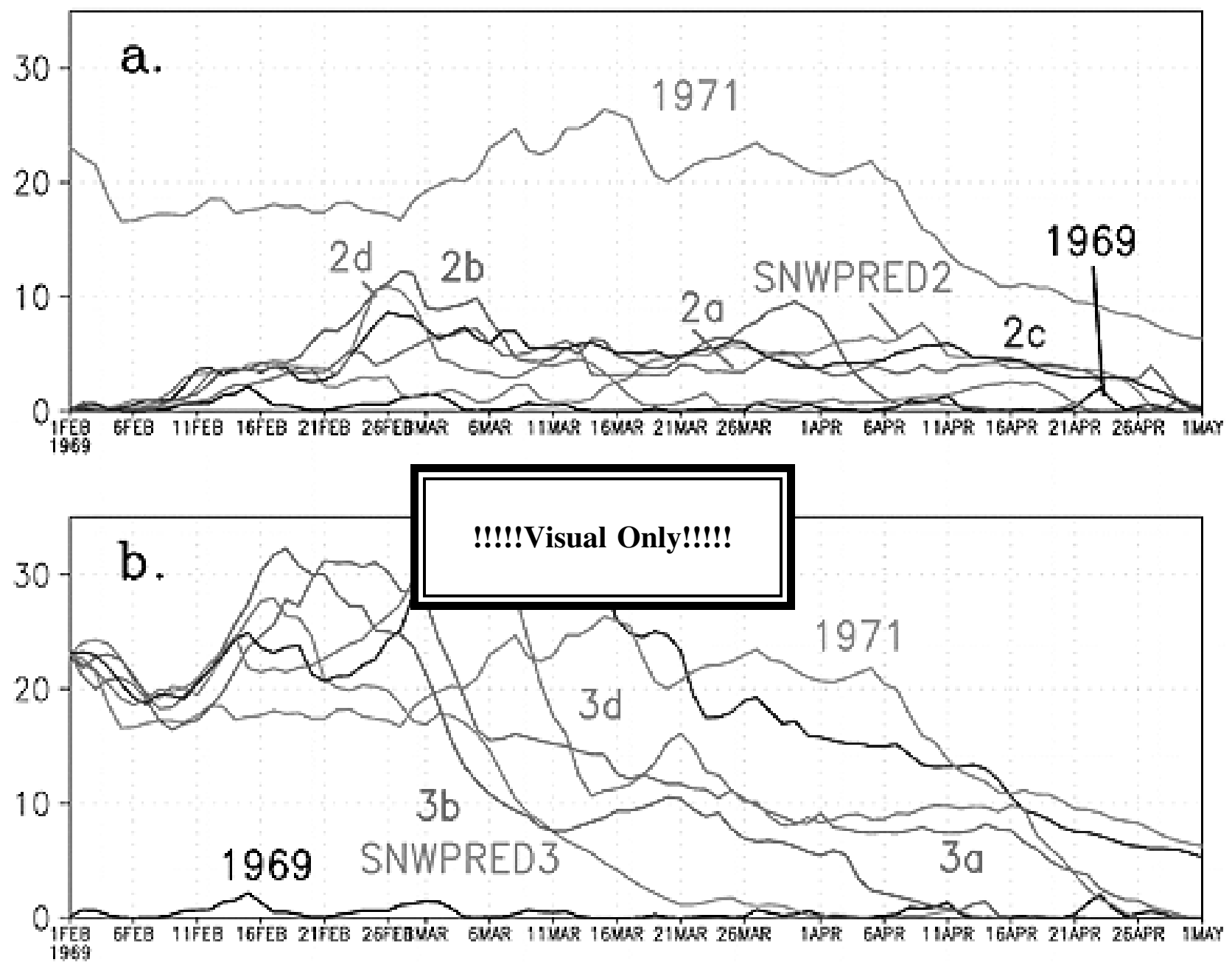

Fig. 3. Time series of SNWPRED2 (low initial snow cover, normal snow atmosphere) and SNWPRED3 (normal initial snow cover, low-snow atmosphere) snow-cover depths ( $\mathrm{mm}$ w.e.) compared to the control low-snow year (1969) and normal-snow year (1971). Experiments labeled a-d correspond to ensemble members using atmospheric initial conditions corresponding to 30 and 31 January, 2 and 3 February respectively.

western U.S.A. This has obvious implications for prediction of seasonal water resources. This work suggests that positive (negative) snow-cover anomalies in mid- to late-winter may lead to positive (negative) snow-cover anomalies later in the season.

\section{$1 \mathrm{~m}$ snow-cover case (1MSNW)}

Physical feedback effects between the snow and the atmosphere (from the 1MSNW case) demonstrate that an anomalously high snow-cover extent tends to maintain conditions favorable for the perpetuation of that snow cover. That is, high land-surface albedos lead to decreased absorption of shortwave radiation at the surface, which, in turn, leads to cooler surface and near-surface air temperatures and decreased snowmelt (Fig. 4a and b). The cooler temperatures and decreased rate of snowmelt lead to greater atmospheric stability, which is conducive to an increase in atmospheric pressure and hence changes in atmospheric circulation (Fig. $4 c)$. On the other hand, a decreased snow extent allows for increased absorption of shortwave radiation at the surface, leading to warmer surface temperatures. The excess energy is then available for snowmelt. This process is clearly seen in our results for the IMSNW case (Fig. 4) and is also evident in the results for the SNWPRED1 and SNWPRED2 cases (not shown).

An alternative or complementary mechanism occurs via the energy required to melt the snowpack. The energy needed to raise snowpack temperature to $0^{\circ} \mathrm{C}$ and to melt/ sublime the snow pack is unavailable to heat the land surface. Subsequently, in high-snow years the overlying atmosphere tends to remain cooler, while in low-snow-cover years such cooling effects are reduced or even absent.

In related work, we performed a study looking at the predictability of soil-moisture status that is analogous to the snow study presented here (Oglesby and others, in press). As opposed to our snow-cover results, in the soil moisture runs the initial state of the atmosphere appears more important than the initial state of soil moisture. Since over seven times as much energy is required to evaporate a given mass of liquid water as to melt the same mass of frozen water, the implication is that the energy required to melt snow cover is not the major cause of the dependency on initial snow-cover state. Rather, the snow albedo effect described earlier appears to be the dominant mechanism.

\section{GONCLUSIONS}

We have performed a series of climate-model experiments aimed at understanding the predictability of snow cover based on a specified initial state. Results from these experiments show that the initial snow cover plays a much more 


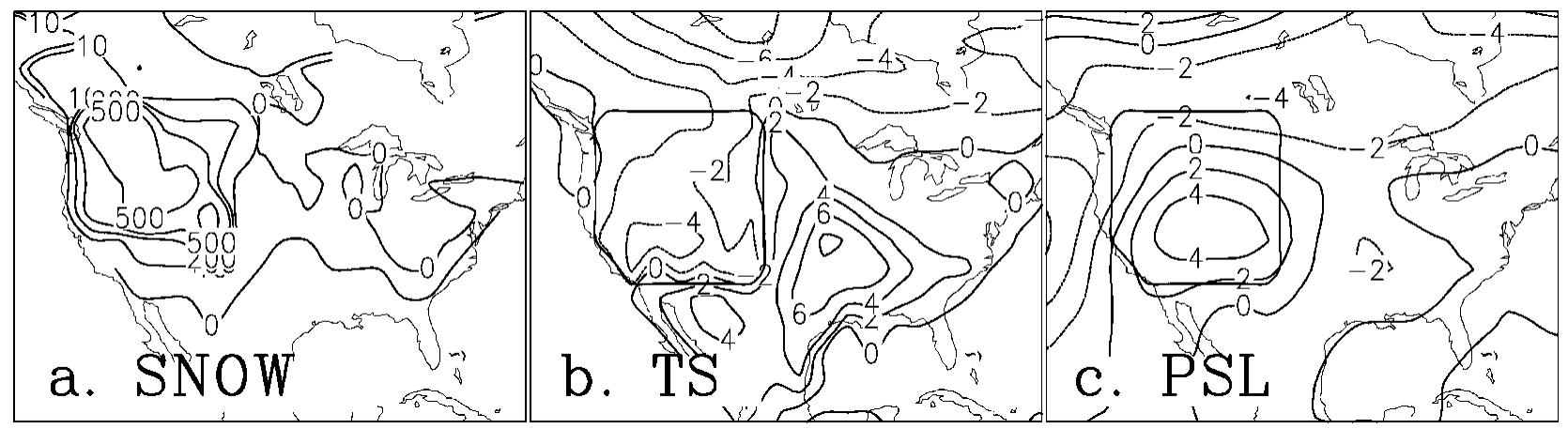

Fig. 4. 1MSNW-1969 (low-snow) anomalies of (a) snow-cover depth ( $m m$ s.w.e.), (b) surface temperature ( $\mathrm{TS}$ in ${ }^{\circ} \mathrm{C}$ ) and (c) sea-level pressure (PSL in mbar) averaged for the month of April.

important role in determining the regional climate than does the initial state of the atmosphere or of the SSTs (although both of these would be important in setting up the initial anomaly). These results also indicate that the snow-cover forcing on the local climate can persist for several weeks and attests to the strength of the snow-cover albedo-temperature feedback on the regional climate.

Future work includes model experimentation to examine the role of late-season (i.e. ablation-season) snow cover in modulating early-summer precipitation anomalies and the summer monsoon in the southwestern U.S.A. We will also expand out from the regional view and look at the role snow cover plays in remote forcing of climate variability, particularly the possible effects of Eurasian snow-cover anomalies on the western U.S. climate.

\section{ACKNOWLEDGEMENTS}

This work was supported by grants from the U.S. National Science Foundation (NSF), the NASA Land Surface Hydrology Program and from the U.S. National Oceanic and Atmospheric Administration (NOAA) Office of Global Programs. In particular, S.M. was supported by NSF grant ATM9901357, NOAA grant NA66GPO268 and NASA grant NAG8-1514 for this study. R.J.O. was supported in this study by NOAA grant NA66GPO278 and NASA grant NAG8-1515. A.W.N. was supported by NSF grant ATM-9900687. Computational resources were provided by the Scientific Computing Division of NGAR under project No. 35851000. NGAR is supported by the NSF.

\section{REFERENCES}

Baker, D. G., D. L. Ruschy, R. H. Skaggs and D. B. Wall. 1992. Air temperature and radiation depressions associated with a snowcover. F. Appl. Meteorol., 31, 247-254.

Barnett, T. P., L. Dumenil, V. Schlese, E. Roeckner and M. Latif. 1989. The effect of Eurasian snow cover on regional and global climate variations. 7. Atmos. Sci., 46(5), 661-685.

Bonan, G. B. 1998. The land surface climatology of the NCAR Land Surface
Model (LSM 1.0) coupled to the NGAR Community Climate Model (CGM3). F. Climate, 11(6), 1307-1326.

Boville, B. A. and P. R. Gent. 1998. The NCAR climate system model, version one. 7. Climate, $11(6), 1115-1130$.

Cayan, D. R. 1996. Interannual climate variability and snowpack in the western United States. F. Climate, 9(5), 928-948.

Clark, M. P. and M. C. Serreze. In press. Effects of variations in east Asian snow cover on modulating atmospheric circulation over the North Pacific Ocean. 7. Climate.

Dewey, K. F. 1977. Daily maximum and minimum temperature forecasts and the influence of snow cover. Mon. Weather Rev., 105, 1594-1597.

Dickson, R. and J. Namias. 1976. North American influence on the circulation and climate of the North Atlantic sector. Mon.Weather Rev., 104(7), 1255-1265.

Foster, J., M. Owe and A. Rango. 1983. Snow cover and temperature relationships in North America and Eurasia. 7. Climate Appl. Meteorol., $22(3), 460-469$.

Groisman, P.Ya., T. R. Karl and R.W. Knight. 1994. Observed impact of snow cover on the heat balance and the rise of continental spring temperatures. Science, 263(5144), 198-200.

Groisman, P.Ya., E. L. Genikhovich, R. S. Bradley and B. M. Ilyin. 1997. Assessing surface-atmosphere interactions using former Soviet Union standard meteorological network data. Part II: Cloud and snow cover effects. F. Climate, 10(9), 2184-2199.

Gutzler, D. S. and J.W. Preston. 1997. Evidence for a relationship between spring snow cover in North America and summer rainfall in New Mexico. Geophys. Res. Lett., 24(17), 2207-2210.

Hack, J.J., J.T. Kiehl and J. Hurrell. 1998. The hydrologic and thermodynamic characteristics of the NCAR CCM3. F. Climate, 11 (6), 1179-1206.

Heim, R., Jr and K. F. Dewey. 1984. Circulation patterns and temperature fields associated with extensive snow cover on the North American continent. Phys. Geogr., 4, 66-85.

Kiehl, J.T., J. J. Hack, G. B. Bonan, B. A. Boville, D. L. Williamson and P. J. Rasch. 1998. The National Center for Atmospheric Research Community Climate Model: GCM3. f. Climate, 11(6), 1131-1149.

Leathers, D. J., A. W. Ellis and D. A. Robinson. 1995. Characteristics of temperature depressions associated with snow cover across the northeast United States. 7. Appl. Meteorol., 34(2), 381-390.

Marshall, S. and R.J. Oglesby. 1994. An improved snow hydrology for GCMs. Part 1: Snow cover fraction, albedo, grain size, and age. Climate Dyn., 10(1-2), 21-37.

Oglesby, R.J., S. Marshall, J. O. Roads and F. R. Robertson. In press. Diagnosing warm season precipitation over the GCIP region from a model and reanalysis. 7. Geophys. Res.

Wagner, A. J. 1973. The influence of average snow depth on monthly mean temperature anomaly. Mon. Weather Rev., 101, 624-626.

Walsh, J. E., D. R. Tueck and M. R. Peterson. 1982. Seasonal snow cover and short-term climate fluctuations over the United States. Mon. Weather Rev., $110(10), 1474-1485$. 